\title{
EDUCAÇÃO AMBIENTAL PARA ADEQUAÇÃO DE PEQUENAS PROPRIEDADES AGRÍCOLAS
}

\author{
Joanne Régis Costa ${ }^{1}$ \\ Adriana Morais Silva ${ }^{2}$ \\ José Edison Carvalho Soares ${ }^{3}$
}

Resumo: A adequação ambiental compreende todas as ações a serem desenvolvidas no imóvel rural, visando delimitar, recuperar, recompor e criar condições para a regeneração da vegetação nativa. Por meio do desenvolvimento de ações educativas, é possível realizar tal adequação.

Neste trabalho, são apresentados os resultados de um projeto desenvolvido pela Embrapa, Ifam (zona leste) e Senar, em um assentamento da reforma agrária, na zona rural de Manaus (AM). O projeto foi desenvolvido com base em princípios metodológicos participativos.

A Educação Ambiental tem representado um instrumento básico para a construção de alternativas. Paulatinamente, as propriedades agrícolas estão sendo adequadas às normas ambientais vigentes, havendo, também, a geração de trabalho e renda para as famílias assentadas.

Palavras-chave: Educação Ambiental; Agricultura Familiar; Código Florestal.

${ }^{3}$ Ifam (zona leste). E-mail: soares-edison@ig.com.br 


\section{Introdução}

Em 25 de maio de 2012, foi publicado o novo Código Florestal Brasileiro (lei $n^{\circ}$. 12.651) que estabelece normas gerais sobre a proteção da vegetação, Áreas de Preservação Permanente (APPs) e Áreas de Reserva Legal (RL). A lei dispõe também sobre a exploração florestal, o suprimento de matéria-prima florestal, o controle da origem dos produtos florestais, a prevenção dos incêndios florestais e prevê instrumentos econômicos e financeiros para o alcance de seus objetivos. Também em 2012, foi publicado o decreto $\mathrm{n}^{\circ} .7 .830$ que dispõe sobre o Sistema de Cadastro Ambiental Rural e estabelece normas de caráter geral aos Programas de Regularização Ambiental.

Para cumprimento dessa legislação, os agricultores precisam incorporar - componente ambiental na estrutura das suas decisões, visando o cumprimento da função social da propriedade rural, ou seja, a utilização adequada dos recursos naturais disponíveis e a preservação do meio ambiente.

A adequação ambiental compreende todas as ações a serem desenvolvidas no imóvel rural, visando delimitar, recuperar, recompor e criar condições para a regeneração da vegetação nativa das áreas de interesse ambiental existentes na propriedade, seja para a preservação dos recursos hídricos e da flora e fauna locais, seja para melhoria da produção agroflorestal. Por meio do desenvolvimento de ações educativas, é possível realizar tal adequação.

A Educação Ambiental (EA) pode ser um instrumento para que grupos sociais intervenham de modo qualificado tanto na gestão do uso dos recursos ambientais quanto na concepção e aplicação de decisões que afetam a qualidade do ambiente (QUINTAS, 2007).

Neste trabalho, apresentamos os resultados de um projeto desenvolvido em assentamento da reforma agrária, na zona rural de Manaus (AM), oportunidade em que a equipe da Embrapa, Ifam (zona leste) e Senar buscaram promover a prevenção e mitigação dos impactos ambientais negativos, por meio da Educação Ambiental.

\section{Metodologia}

Este projeto foi desenvolvido com base em princípios metodológicos participativos e na pesquisa-ação. $O$ projeto atuou com a comunidade Buriti localizada no Assentamento Tarumã-Mirim, zona rural de Manaus (AM), de 2011 a 2015.

A pesquisa-ação é um tipo de pesquisa social que é concebida e realizada em estreita associação com uma ação ou com a resolução de um problema coletivo e no qual os pesquisadores e os participantes representativos da situação da realidade a ser investigada estão envolvidos de modo cooperativo e participativo. A pesquisa-ação procura gerar na comunidade um processo de auto-diagnóstico e auto-transformação na busca 
da sensibilização acerca dos problemas vivenciados, de suas causas e soluções para as necessárias mudanças (THIOLLENT, 2003; 1995;1985). A pesquisa-ação exige uma estrutura de relação entre os pesquisadores e pessoas envolvidas no estudo da realidade do tipo participativo/coletivo.

A participação dos pesquisadores é explicitada dentro do processo do "conhecer" com os "cuidados" necessários para que haja reciprocidade/complementariedade por parte das pessoas e grupos implicados, que têm algo a "dizer e a fazer". Nesta perspectiva, é necessário definir com precisão, quais ações, agentes, objetivos e obstáculos, qual exigência de conhecimento a ser produzido em função dos problemas encontrados na ação ou entre os atores da situação (THIOLLENT,1985). Em síntese, para Thiollent (2005), a pesquisaação se caracteriza:

a) por uma ampla e explícita interação entre pesquisadores e pessoas implicadas na situação investigada;

b) desta interação resulta a ordem de problemas a serem pesquisados e das soluções a serem encaminhadas sob forma de ação concreta;

c) o objetivo de investigação é constituída pela situação social e pelos problemas de diferentes naturezas encontrados nessa situação;

d) o objetivo da pesquisa-ação consiste em resolver ou, pelo menos, em esclarecer os problemas da situação observada;

e) há, durante o processo, um acompanhamento das decisões, das ações e de toda atividade intencional dos atores da situação;

f) a pesquisa-ação não se limita a uma forma de ação (risco de ativismo). Pretende-se aumentar o conhecimento dos pesquisadores e o conhecimento ou 'nível de consciência' das pessoas dos grupos considerados.

Logo, o conhecimento acerca da comunidade e das propriedades agrícolas se deu a partir da inserção da equipe na realidade local. $O$ Diagnóstico Rural Participativo (DRP) (BUARQUE, 2002), o Diagnóstico Agroflorestal do Inpa (não publicado) e o Diagnóstico \& Desenho do ICRAF (RAINTREE, 1987) foram instrumentos usados como base para compreender o contexto político, a organização sociocultural, produção (tipos de cultivos, relações de produção, processos de trabalho), econômicas, ambientais etc. Com base nos diagnósticos, as famílias juntamente com a equipe construíram o Planejamento Participativo para cada propriedade agrícola. A família foi a responsável pela implementação das ações que iam sendo executadas de forma paulatina.

A equipe realizou reuniões, rodas de conversa, oficinas, visitas periódicas in loco, com os objetivos de discutir temas variados. Foram realizadas avaliações, constantes, a fim de compreender como as ações estavam sendo conduzidas pelas famílias, problemas observados, possíveis soluções, alterações de práticas, resultados alcançados etc. 
Ao final do projeto, foram apresentados e discutidos os resultados, os avanços e as novas prioridades para as famílias e para a pesquisa.

\section{Resultados e discussão}

O projeto apresentou uma natureza dinâmica, estando sempre em avaliação e atualização, com uma base epistemológica associada ao diálogo. A valorização do diálogo, do conhecimento e da participação dos agricultores permitiu maior interação e levou à apropriação dos processos de construção e também aos resultados obtidos. Por meio dos diálogos, das interações, do conhecimento partilhado, priorizou-se a inserção do indivíduo no processo educativo e a inserção social, conforme FREIRE (1986).

Freire considera o ser humano inacabado, o que torna o processo educativo constante e contínuo. Segundo o autor, a reflexão deve ser parte inerente da educação, pois só assim o ser humano deixa de ser objeto e passa a ser sujeito.

Quando o homem compreende sua realidade, pode levantar hipóteses sobre o desafio dessa realidade e procurar soluções. Assim, pode transformá-la e com seu trabalho pode criar um mundo próprio: seu eu e suas circunstâncias" (FREIRE, 1979b).

Buscou-se sensibilizar os envolvidos para trabalhar com os elementos naturais (água, ar, solo, flora, fauna e ser humano) de forma integrada. A EA facilitou a compreensão dos múltiplos aspectos da comunidade, interrelacionando as questões ambientais, sociais e econômicas. Observou-se uma forte mobilização dos comunitários envolvidos para o equacionamento dessas questões.

Várias ações de Educação Ambiental foram realizadas com a participação dos assentados e as atividades impactantes, especialmente a produção carvoeira, o desmatamento ilegal $e$ as queimadas, foram, paulatinamente, sendo substituídas. Houve o plantio de mudas de espécies frutíferas e madeiráveis para recomposição das APPs e áreas de Reserva Legal, o manejo da regeneração natural, os plantios de sistemas agroflorestais comerciais em áreas abandonadas e os plantios de hortaliças, o que levou ao aumento da produção de alimentos com geração de renda e de serviços ambientais.

Conforme Bahia (2013), a Educação Ambiental feita fora dos espaços formais de ensino se constitui de processos educativos voltados à mobilização, sensibilização, capacitação, organização e participação individual e coletiva, na construção de sociedades sustentáveis.

Em Reigota (2010), se encontra o posicionamento que trata-se de uma EA que visa não só a utilização racional dos recursos naturais, mas basicamente a participação dos cidadãos nas discussões e decisões sobre a questão ambiental. Os processos participativos favoreceram o entendimento do

revista brasileira educação ambiental 
contexto, aprofundaram a interpretação dos problemas e permitiram a identificação dos melhores caminhos a serem traçados para chegar até as soluções.

A equipe buscou incentivar a troca de experiências, a fim de possibilitar - aprendizado ao discutir questões como geração de renda, segurança alimentar, inclusão social, gestão dos recursos hídricos, conservação de solo, recuperação de áreas degradadas, legislação ambiental entre outras.

Outros resultados observados ao longo do processo educativo: a integração entre os agricultores; as mudanças nos sistemas de plantio e adequação à agricultura orgânica; o desmatamento evitado; maior consumo de produtos orgânicos; permanência das famílias do projeto no assentamento; evitando o retorno para a capital, o que era mencionado no início das atividades, a melhoria do apoio do poder público local à comunidade.

Além disso, foram ministradas palestras nas escolas do assentamento e foi doada à principal escola local uma minibiblioteca com livros técnicos da Embrapa e livros infantis com temática ambiental.

Alguns aspectos importantes do projeto foram: a multidisciplinaridade envolvendo diversos atores e parcerias institucionais; as atividades focadas na valorização da mulher, pois havia mais mulheres participando das atividades; o aprendizado teórico e o aprendizado prático em cada atividade; a geração de trabalho e renda para as famílias; a inserção de produtos agrícolas no comércio local e a criação de pontos de comercialização por articulação própria; a oportunidade de intercâmbio entre agricultores; a emancipação do grupo na gestão do negócio, podendo por si próprio tomar decisões.

Verificou-se que a Educação Ambiental cumpre um papel importante no sentido de embasar a construção de mudanças, isto é, a recuperação, conservação e melhoria do meio ambiente e a qualidade de vida de cada um e de todos (MARANHÃO; SORRENTINO, 2009). Uma ação de Educação Ambiental orientada na perspectiva de promover processos educacionais e ambientalistas que tenham permanência e continuidade deve ser o ponto principal para a manutenção desses resultados (SANTOS; DIAS, 2015).

Os benefícios vindos da adoção de boas práticas associadas à preservação dessas áreas extrapolaram as delimitações da propriedade, adquirindo importância socioambiental com impactos nas comunidades vizinhas.

\section{Conclusões}

A Educação Ambiental atua como um processo mediador de interesses e conflitos e de construção de ações preventivas e corretivas realizadas na propriedade agrícola e/ou na comunidade.

A EA é, portanto, um instrumento por meio do qual podem ser 
De forma paulatina, as propriedades rurais estão sendo adequadas às normas ambientais, podendo futuramente, tornarem-se unidades demonstrativas de adequação agroambiental.

\section{Referências}

BAHIA. Secretaria do Meio Ambiente. Programa de Educação Ambiental do Estado da Bahia: PEABA. Salvador: EGBA, 2013.

BRASIL. Código florestal. Disponível em: $<$ http://www2.planalto.gov.br/imprensa/entrevistas/apresentacao-dos-ministrossobre-o-codigo-florestal> Acesso em: 16 de junho de 2017.

BUARQUE, S. Construindo o desenvolvimento local sustentável. Rio de Janeiro: Garamond. 2002.

FREIRE, P. Educação como prática da liberdade. São Paulo: Editora Paz e Terra. 1992.

FREIRE, P. Medo e Ousadia. Rio de Janeiro: Paz e Terra, 1986.

FREIRE, P. Educação e mudança. 2․․ ed. Rio de Janeiro: Paz e Terra, 1979b.

MARANHÃO, R.R.; SORRENTINO, M. Educação ambiental e mobilização social em saneamento. In: BRASIL. Ministério das Cidades. Secretaria Nacional de Saneamento Ambiental. Programa de Modernização do setor de Saneamento (PMSS). Lei Nacional de Saneamento Básico: perspectivas para as políticas e a gestão dos serviços públicos. Livro III. Conceitos, características e interfaces dos serviços públicos de saneamento básico. Coletânea: Brasília, 2009.

RAINTREE, J.B. D \& D user's manual: an introduction to agroforestry diagnosis and design. Nairobi: ICRAF, 1987. 110 p.

QUINTAS, J.S. Educação na gestão ambiental pública. In: FERRARO JÚNIOR, L. A. (Org.). Encontros e caminhos: formação de educadoras (es) ambientais e coletivos educadores. Brasília: MMA, DEA, v. 2. p. 131-142, 2007.

REIGOTA, M. Meio Ambiente e Representação Social. $8^{\circ}$ ed. São Paulo: Cortez, 2010.

SANTOS, J.L.A.; DIAS, S.M.F. Análise da percepção de atores envolvidos em programa de educação ambiental aplicado na implantação de cisternas rurais. Revbea, São Paulo, V. 10, № 3: 41-59, 2015.

THIOLLENT, M. Metodologia da pesquisa-ação. São Paulo: Cortez. 2005.1995.1985.

THIOLLENT, M. (Org). Extensão Universitária: conceitos, métodos e práticas. UFRJ. Sub-Reitoria de Desenvolvimento e Extensão. Rio de Janeiro: 2003. 